nialism. A serious dialogue between literary studies and cultural studies can benefit both.

\section{CARY NELSON}

University of Illinois, Urbana

In the introduction to Cultural Studies ([New York: Routledge, 1992] 1-16), the monumental volume from the 1990 Champaign-Urbana conference, Cary Nelson, Paula A. Treichler, and Lawrence Grossberg state in passing that "although there is no prohibition against close textual readings in cultural studies, they are also not required." A slightly grudging Venn diagram is being sketched out here: close readers can overlap with cultural studies if they must. "No prohibition"- - whence a new formula for acknowledgments sections: "We thank cultural studies for generously giving permission for this book's occasional dependence on a close reading." To judge by the desksagging weight of the cultural studies anthologies that have appeared over the last few years, there won't be much time, never mind inclination, for close reading anyway. This damning with faint inclusion occurs after a high-sounding reference to "the heritage of disciplinary investments and exclusions and a history of social effects that cultural studies would often be inclined to repudiate." Close textual readings are the chosen illustration of this unfortunate heritage and history, singled out as more guilty than most of the exclusions and exclusiveness that cultural studies seeks to avoid. But after the sentence not prohibiting close readings, there comes a further charge: "Moreover, textual analysis in literary studies carries a history of convictions that texts are properly understood as wholly self-determined and independent objects as well as a bias about which kinds of texts are worthy of analysis. That burden of associations cannot be ignored" (2). Now the problem is not the way that literary analysis operatesthrough close reading - but the objects it operates on and the assumptions it makes about their conditions of existence and their value. And this time there will be no turning of a blind eye; this hangover "cannot be ignored."

The authors of the introduction draw a nervous distinction between cultural and literary studies, ignoring the fact that the history of literary criticism is as diverse and contested as the practices of the rather younger discipline of cultural studies. It is as though cultural studies were afraid of being sucked into a celebration of Great Works at the very mention of the word literature. Analogously, literary studies seems to fear being swallowed up by an all-devouring, all-leveling new disciplinary force that refuses it the right to ask other than self-evidently social or political questions of its texts.
If cultural studies can represent itself as the locus of social critique, as opposed to a quiescent literary criticism forever closely reading its canon, disaffected literary people can identify with cultural studies as the cutting edge of what they see as their complacent discipline. But this is not a new formation for literary studies. Literary criticism has often been accused of being indifferent to cultural concerns, and there have always been tendencies in literary studies to open close reading: to make reading politically relevant or to place texts in frames wider than or different from those encompassing whatever are identified at the time as literary concerns. Semiotics was a field that situated literature as exemplary for examining how cultural meanings are made. Before that, sociology, especially Marxist sociology, promised to make literary studies political. With the advent of theory and then the "turn to history" in literary studies, sociology more or less dropped out of discursive sight, to be mentioned only as a distant domain of benighted number crunchers. Then along came cultural studies to assert the pertinence of contemporary social analysis, incorporating into its anthologies the work of writers historically associated with various forms of radical sociology.

In the work of such writers as Benjamin or de Certeau, close reading of cultural texts becomes creative sociology: the reading changes the object, shows it up in a new perspective. Here is a place where cultural studies can and does meet literary studies on common, critical ground. By prompting unfamiliar questions and juxtapositions, close reading can discover and make connections between as well as within diverse texts. The objects of study may be imaginative writings, with a history of interpretations and with established cultural value, noncanonical writings, or writings from any cultural field where close reading may yield new perspectives not available through other methodologies. To use the same method in reading a poem, a newspaper editorial, and a piece of philosophy is not necessarily to treat literature of different kinds as the same sort of matter. Closely reading nonliterary writing doesn't imply an aesthetic valuation of that writing any more than asking a cultural question of an established literary text implies that the text is no different in its history or its provenance from, say, an extract from a marketing textbook. Not all literary work is cultural studies, and not all cultural studies involves modes or objects of reading that are literary. But the area in which the circles cross can unsettle both fields in potentially challenging ways-as the awkwardness of "no prohibition" suggests.

RACHEL BOWLBY University of Sussex 